\title{
IMPLEMENTASI SISTEM PAKAR PENGENDALIAN INTERNAL PEMBERIAN KREDIT RUMAH MENGGUNAKAN METODE FORWARD CHAINING
}

\author{
Tika Christy ${ }^{1}$, Febby Madonna Yuma ${ }^{1 *}$, Zulfan Efendi $^{1}$ \\ ${ }^{1}$ Sistem Informasi, Sekolah Tinggi Manajemen Informatika dan Komputer Royal \\ Email :*febbyyuma@gmail.com
}

\begin{abstract}
Abstrak: Tujuan praktis dari kecerdasan buatan adalah membuat komputer lebih bermanfaat bagi manusia. Kecerdasan buatan dapat membantu manusia membuat keputusan, menemukan informasi yang lebih akurat atau membuat komputer lebih mudah digunakan dengan tampilan alami untuk membuatnya mudah dimengerti. Pada kenyataannya, sistem permohonan kredit bertujuan untuk memberikan kemudahan serta layanan yang tepat sesuai kebutuhan nasabah, dan juga memberikan suatu pedoman serta syarat-syarat dalam permohonan kredit dengan jelas agar nasabah mengerti bagaimana prosedur dalam mengajukan permohonan kredit. Adapun resiko yang dihadapi dari Bank SUMUT seperti tunggakan kredit atau kredit macet. Oleh karena itu, dibutuhkanlah kecermatan pihak internal bank dalam melakukan analisa. Ini bertujuan untuk mempelajari Sistem Pakar dengan metode Forward Chaining dan masalah untuk mengetahui apakah tindakan yang akan diambil oleh pihak internal dalam memproses pemberian kredit rumah sesuai aturannya.
\end{abstract}

Kata kunci: kredit; runut maju; sistem pakar

\begin{abstract}
The practical goal of artificial intelligence is to make computers more useful to humans. Artificial intelligence can help humans make decisions, find more accurate information or make computers easier to use with natural displays to make them easy to understand. The credit application system aims to provide convenience and appropriate services according to customer needs, and also provides clear guidelines and conditions for credit applications so that customers understand the procedure for applying for credit. The risks faced by Bank SUMUT such as credit arrears or bad loans. Therefore, it takes the accuracy of the bank's internal parties in conducting the analysis. This aims to study the Expert System with the Forward Chaining method and the problem to find out whether the actions that will be taken by internal parties in processing home loans are following the rules.
\end{abstract}

Keywords: credit; expert system; forward chaining 



\section{PENDAHULUAN}

Cabang ilmu komputer yang dapat membantu manusia adalah kecerdasan buatan atau Artificial Intelligence. Tujuan praktis dari kecerdasan buatan ini adalah membuat komputer lebih bermanfaat bagi manusia. Kecerdasan buatan dapat membantu manusia membuat keputusan, menemukan informasi yang lebih akurat atau membuat komputer lebih mudah digunakan dengan tampilan alami untuk membuatnya mudah dimengerti. pada dasarnya sistem pakar adalah program yang menggabungkan basis pengetahuan dengan sistem penalaran, dan merupakan bagian dari kecerdasan buatan. Sistem pakar dirancang untuk memberikan saran dan bantuan pemecahan masalah untuk bidang profesional tertentu. Rencana tersebut akan bertindak sebagai penasihat atau konsultan yang cerdas dalam lingkungan keterampilan tertentu [1].

Sistem Pakar merupakan sistem komputer yang mengadopsi pengetahuan manusia yang bekerja berdasarkan rule atau aturan yang diambil dari pemahaman seseorang yang dapat menyelesaikan suatu perma-salahan tertentu [2] [3] . Didalam komponen sistem pakar terdapat sebuah metode yang digunakan untuk memasukkan pengetahuan pakar ke dalam sebuah sistem. Forward chaining merupakan proses runut maju yang menarik kesimpulan dari beberapa fakta atau data [4]-[6].

Pada kenyataannya, sistem permohonan kredit bertujuan untuk memberikan kemudahan serta layanan yang tepat sesuai kebutuhan nasabah, dan juga memberikan suatu pedoman serta syarat-syarat dalam permohonan kredit dengan jelas agar nasabah mengerti bagaimana prosedur dalam mengajukan permohonan kredit. Selain itu, pihak internal harus mampu memahami tugasnya sebagai pihak manajemen yang mengambil keputusan [7].

Bank Sumut memberikan fasilitas pelayanan Kredit Pemilikan Rumah yang diperuntukkan bagi perorangan yang memenuhi syarat dalam membeli tanah dan rumah dengan standar bangunan minimal dengan ketentuan Rumah Sederhana (RS). Adapun resiko yang dihadapi dari Bank Sumut seperti tunggakan kredit atau kredit macet. Oleh karena itu, dibutuhkanlah kecermatan pihak internal bank dalam melakukan analisa. Ini bertujuan untuk mempelajari Sistem Pakar dengan metode Forward Chaining dan masalah untuk mengetahui apakah tindakan yang akan diambil oleh pihak internal dalam memproses pemberian kredit rumah sesuai aturannya.

Berdasarkan

penelitian

sebelumnya yang dilakukan [8] menjelaskan bagaimana sistem dan prosedur pembiayaan KPR Syariah dengan akad murabahah yang diterapkan pada PT. BTN Syariah cabang jombang dalam mendukung pengendalian intern. Penelitian yang dilakukan [4] aplikasi sistem pakar yang dibuat dapat membantu mekanik akan mekanisme kerja alat berat sehingga mereka bisa menangani masalah-masalah pada alat berat tersebut. Pada penelitian [9] salah satu penyebab kredit bermasalah adalah kurang telitinya pihak bank dalam hal survei dan analisa pemberian kredit. risiko yang dapat terjadi pada perusahaan berkaitan dengan sistem penjualan kredit seperti pembatalan pembelian kredit yang dilakukan oleh pembeli dan terlambat membayar utang yang telah jatuh tempo atau bahkan 
DOI: https://doi.org/10.33330/jurteksi.v7i3.1269

Available online at http://jurnal.stmikroyal.ac.id/index.php/jurteksi

keterlambatan proses pengantaran barang [10].

\section{METODE}

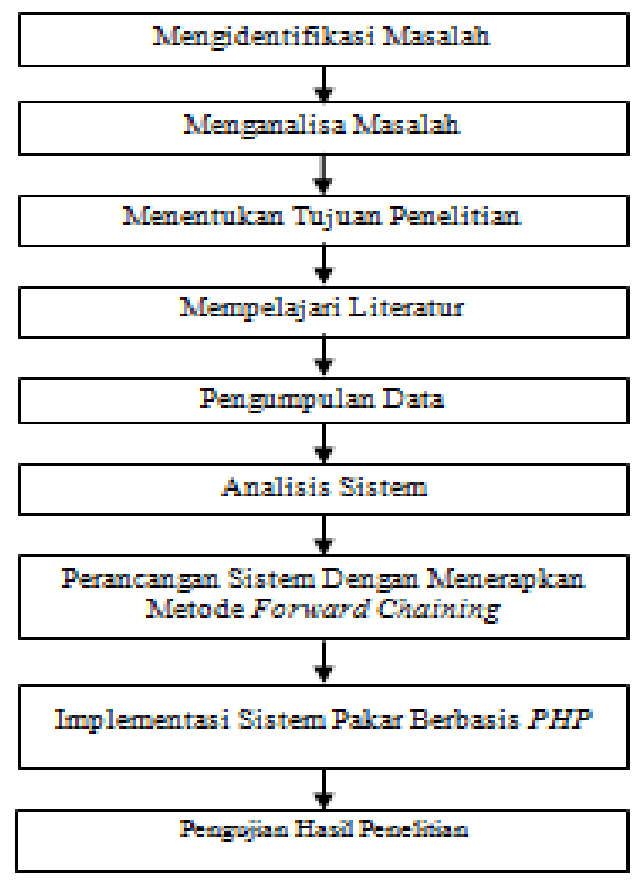

Gambar 1. Kerangka Penelitian

\section{Mengidentifikasi Masalah}

Dalam proses identifikasi masalah harus ditentukan ruang lingkup permasalahan agar dapat menentukan solusi terbaik dari permasalahan yang ada.

\section{Menganalisa Masalah}

Sebelum melakukan penelitian, ruang lingkup masalah harus ditentukan terlebih dahulu agar dapat ditentukan solusi terbaik dari masalah tersebut. Setelah memahami masalah, maka ditentukan tujuan yang akan dicapai dari penelitian ini.

\section{Menentukan Tujuan Penelitian}

Tujuan yang akan dicapai dari penelitian ini yaitu: a. Untuk merancang Sistem Pakar yang menggunakan Rule serta menggunakan metode Forward Chaining untuk Pengendalian Internal terhadap pemberian Kredit Pemilikan Rumah kepada nasabah berbasis .

b. Membuat suatu sistem aplikasi berbasis PHP yang dapat digunakan oleh karyawan Bank Sumut khususnya di bagian Account Officer atau bagian Kredit Pemilikan Rumah dalam membantu memberikan keputusan terhadapa pemberian kredit rumah

\section{Mempelajari Literatur \\ Mempelajari literatur bertujuan untuk lebih mengetahui pengetahuan- pengetahuan atau Knowledge yang akan diterapkan dalam Sistem Pakar ini.}

\section{Pengumpulan Data}

Pengumpulan data dan informasi pada tahap ini dilakukan untuk mengetahui, mendapatkan data dan informasi yang nantinya akan mendukung penelitian ini.

\section{Analisis Sistem}

Pada tahap ini dilakukan analisa dari data-data yang sudah diperoleh kemudian dilakukan pengujian berdasarkan proses yang ada sehingga tujuan yang di inginkan bisa tercapai.

\section{Perancangan Sistem Dengan Menerapkan Metode Forward Chaining}

Pada tahap ini akan dibahas tentang perancangan dari model sistem dengan menentukan rancangan Input, Output dan Rule-Rule yang akan digunakan dalam menentukan solusi dalam pemberian Kredit Pemilikan Rumah. 


\section{Implementasi Sistem Pakar Berbasis} PHP

\begin{tabular}{llr}
\multicolumn{1}{c}{ Tahap } & \multicolumn{1}{c}{ berikutnya } & setelah \\
dilakukan & perancangan & dan \\
pembangunan & sistem yaitu & tahap
\end{tabular} pengujian sistem, hal ini bertujuan untuk melihat sejauh mana metode Forward Chaining ini mampu memecahkan masalah dalam menangani permasalahan kredit macet dari nasabah oleh pihak Account Officer Bank SUMUT. Pengujian ini dilakukan dengan cara mencoba menggunakan sistem berbasis website tersebut yang telah dihosting ke internet dengan mengakses alamat IP (Internet Protocol) yang telah ditetapkan pada PC Server.

\section{Pengujian Hasil Penelitian}

Pengujian dilakukan untuk membandingkan hasil yang didapatkan pada tahap implementasi sistem. Apakah hasil yang didapat sesuai dengan pengujian yang dilakukan.

\section{HASIL DAN PEMBAHASAN}

\section{Analisa Masalah}

Analisa masalah merupakan tahapan awal yang harus dilakukan sebelum melakukan perancangan aplikasi. Pada tahap ini, pencarian informasi tentang permasalahan yang selalu dialami oleh pihak internal dalam memproses pemberian kredit rumah sesuai aturannya. Dimulai dengan Memahami terlebih dahulu bagaimana prosedur dalam permohonan kredit pemilikan rumah serta mengetahui syarat-syarat dalam permohonannya mulai dari ketentuan, bunga, kriteria nasabah, hingga proses permohonan disetujui. Setelah mengetahui permasalahan yang ada, dapat digambarkan apa saja yang dibutuhkan dalam proses perancangan aplikasi sistem pakar pengendalian internal pemberian kredit rumah sesuai aturan.

\section{Analisa Kebutuhan Sistem}

Tahap awal ini adalah analisa kebutuhan sistem yaitu tahap bagaimana sistem yang akan dihasilkan dan sesuai dengan kebutuhan internal dan sangat diharapkan sistem yang dibangun sesuai dengan aturan perusahaan dalam melakukan analisa kebutuhan. Sistem Pakar yang dibuat berguna untuk mengetahui, mencari serta menemukan solusi untuk membantu nasabah dalam proses Kredit Pemilikan Rumah baik itu nasabah reguler, karyawan, pengusaha, dan lain-lain, yang nantinya menghasilkan kesimpulan apakah permohonan KPR disetujui atau ditolak dalam waktu yang tidak terlalu lama.

Sistem Pakar untuk pengendalian pihak internal dalam pemberian Kredit Pemilikan Rumah ini dimulai dengan sebuah basis pengetahuan. Pengetahuan berasal dari Seorang Pakar (Account Officer) yang akan direpresentasikan ke dalam bentuk suatu pengetahuan. Dalam penelitian ini, proses inferensi yang digunakan adalah pelacakan runut maju (Forward Chaining), dengan sekumpulan data yang diproses menuju suatu kesimpulan. Pengumpulan data mulai didapatkan dengan cara wawancara langsung dengan pihak Account Officer divisi KPR, melakukan studi literatur dengan pertanyaan pengajuan KPR, syarat-syarat KPR, kategori KPR, serta macammacam permasalahan kredit macet KPR dan solusi dalam pengendalian internal dalam pemberian KPR, agar untuk kedepannya data yang diperoleh sesuai dengan standar pengajuan.

\section{Mesin Inferensi (Inference Engine) Pengendalian internal atas}


pemberian Kredit Pemilikan Rumah dalam Sistem Pakar penelitian ini menggunakan mesin inferensi Forward Chaining, mesin inferensi ini bekerja dengan cara mencocokkan antara If Part dari Rule yang ada pada knowledge base dengan fakta yang terdapat dalam database . Rule yang sudah ada akan dieksekusi dan then part dari rule tersebut kemudian disimpan menjadi part yang baru dan disimpan ke dalam database.

Dalam kasus ini fakta yang ada dalam database untuk pengendalian internal terhadap KPR terdiri dari tiga tabel yaitu tabel kategori, syarat, dan suku bunga. Pada tabel kategori terdiri dari (N001, N002, N003, N004), pada tabel syarat terdiri dari (S001, S002, S003, S004, S005, S006, S007, S008, S009, S010, S011, S012, S013, S014), dan tabel suku bunga KPR terdiri dari (B001, B002, B003, B004, B005). Kesimpulan dari pengendalian internal ini ialah berupa solusi yang mana di dapat dari masing-masing dari suku bunga yang diambil oleh nasabah.

Berdasarkan pada Sistem Pakar berbasis aturan, maka desain arsitektur Sistem Pakar dalam pengendalian internal atas pemberian Kredit Pemilikan Rumah dapat dilihat pada gambar 2:

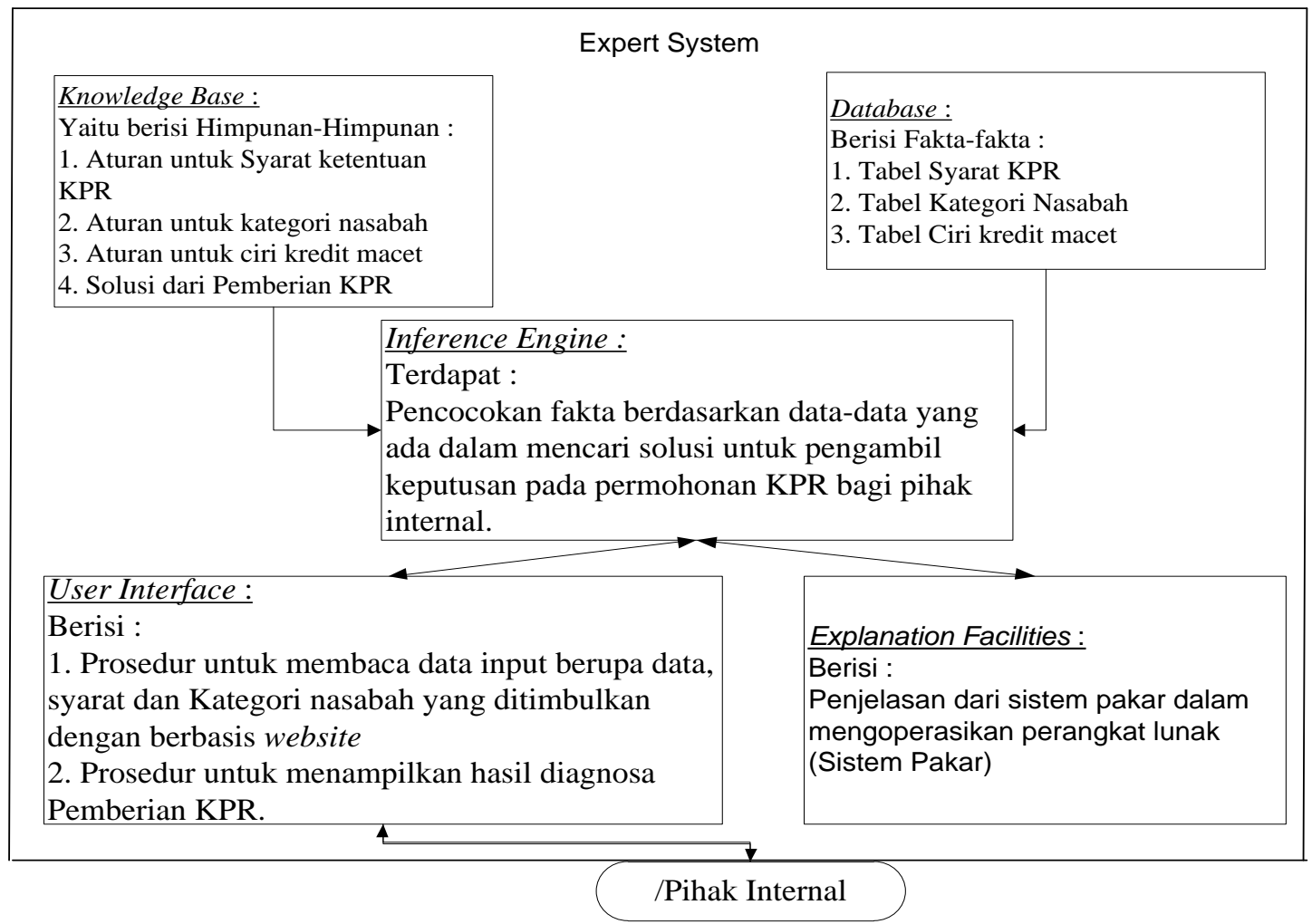

Gambar 2. Komponen Sistem Pakar 
Tabel 1. Tabel Hasil Pengujian Rule

\begin{tabular}{|c|c|c|c|c|c|}
\hline No & Rule & $\begin{array}{l}\text { Kategori } \\
\text { Nasabah }\end{array}$ & $\begin{array}{c}\text { Syarat- } \\
\text { syarat }\end{array}$ & $\begin{array}{c}\text { Suku } \\
\text { Bunga }\end{array}$ & Solusi \\
\hline 1 & R1 & N001 & $\begin{array}{l}\text { S001, } \\
\text { S002, } \\
\text { S003, } \\
\text { S004, } \\
\text { S005, } \\
\text { S006, } \\
\text { S007. }\end{array}$ & $\begin{array}{c}\text { B001 } \\
\text { atau } \\
\text { B002 }\end{array}$ & $\begin{array}{l}\text { S001 atau S002 = Permohonan diterima } \\
\text { karena syarat sudah dilengkapi dan jika } \\
\text { nasabah dapat melakukan pelunasan } \\
\text { dipercepat maka tidak dikenakan } \\
\text { penalty. }\end{array}$ \\
\hline 2 & $\mathrm{R} 2$ & N002 & $\begin{array}{l}\text { S001, } \\
\text { S002, } \\
\text { S004, } \\
\text { S008 }\end{array}$ & $\begin{array}{c}\text { B001 } \\
\text { atau } \\
\text { B002 }\end{array}$ & $\begin{array}{l}\text { S001 atau S002 = Permohonan diterima } \\
\text { karena syarat sudah dilengkapi dan jika } \\
\text { nasabah dapat melakukan pelunasan } \\
\text { dipercepat maka tidak dikenakan } \\
\text { penalty. }\end{array}$ \\
\hline 3 & R3 & N003 & $\begin{array}{l}\text { S001, } \\
\text { S002, } \\
\text { S004, } \\
\text { S006, } \\
\text { S009 }\end{array}$ & $\begin{array}{l}\text { B003, } \\
\text { B004, } \\
\text { B005 }\end{array}$ & $\begin{array}{l}\text { S003 = Permohonan diterima karena } \\
\text { syarat sudah dilengkapi dan jika nasabah } \\
\text { dapat melakukan pelunasan dipercepat } \\
\text { maka akan dikenakan penalty sebesar } \\
1 \% \text {. S004 atau S005 = Permohonan } \\
\text { diterima karena syarat sudah dilengkapi } \\
\text { dan jika nasabah dapat melakukan } \\
\text { pelunasan dipercepat sebagian / seluruh } \\
\text { sebelum masa programnya habis maka } \\
\text { akan dikenakan penalty sebesar } 2 \% \text {. }\end{array}$ \\
\hline 4 & $\mathrm{R} 4$ & N004 & $\begin{array}{l}\text { S010, } \\
\text { S011, } \\
\text { S012, } \\
\text { S013, } \\
\text { S014 }\end{array}$ & C004 & $\begin{array}{l}\text { S003 = Permohonan diterima karena } \\
\text { syarat sudah dilengkapi dan jika nasabah } \\
\text { dapat melakukan pelunasan dipercepat } \\
\text { maka akan dikenakan penalty sebesar } \\
1 \% \text {. S004 atau S005 = Permohonan } \\
\text { diterima karena syarat sudah dilengkapi } \\
\text { dan jika nasabah dapat melakukan } \\
\text { pelunasan dipercepat sebagian / seluruh } \\
\text { sebelum masa programnya habis maka } \\
\text { akan dikenakan penalty sebesar } 2 \% \text {. }\end{array}$ \\
\hline
\end{tabular}

\section{SIMPULAN}

Dengan Metode Forward Chaining yang di rancang mampu memberikan solusi bagi nasabah dalam proses permohonan KPR di masing-masing cabang Bank SUMUT, Sistem Pakar untuk pengendalian internal atas pemberian KPR berjalan dengan baik, Aplikasi Sistem Pakar ini dapat memberikan solusi dalam mengatasi kredit macet dan memudahkan pihak Account Officer dalam pemilihan supaya lebih selektif dalam pemberian KPR kepada nasabah.

\section{DAFTAR PUSTAKA}

[1] R. Resmiati and A. D. Supriatna, "Pengembangan Sistem Pakar Diagnosis Penyakit Cabai Paprika Berbasis Android," J. Algoritm., vol. 13, no. 1, pp. 191-197, 2016, 
doi: $\quad$ 10.33364/algoritma/v.131.191 .

[2] A. Yaqin and E. Utami, "Sistem Pakar Pemetaan Kelas Siswa LBB 'abc' Menggunakan Metode Forward Chaining," Creat. Inf. Technol. J., vol. 1, no. 1, p. 36, 2015 , doi: 10.24076/citec.2013v1i1.8.

[3] R. E. Putri, K. Molly Morita, and Y. Yusman, "Penerapan metode forward chainig pada sistem pakar untuk mengetahui kepribadian seseorang," INTECOMS J. Inf. Technol. Comput. Sci., vol. 3, no. 1, p. 7, 2020, [Online]. Available: https://journal.ipm2kpe.or.id/inde x.php/INTECOM/article/view/133 2.

[4] T. Christy and I. Syafrinal, "Sistem Pakar Diagnosa Kerusakan Pada Alat Berat Menggunakan Metode Forward Chaining," JURTEKSI (Jurnal Teknol. dan Sist. Informasi), vol. 6, no. 1, pp. 93-100, 2019, doi: 10.33330/jurteksi.v6i1.449.

[5] T. Christy, "Implementasi sistem pakar diagnosa penyakit cabe menggunakan metode forward chaining," TMIK R., vol. 15, no. 1, pp. 353-358, 2018.

[6] R. Noviardi, "Sistem Pakar Berbasis Web Menggunakan Metode Forward Chaining Dalam Menganalisa Kerusakan Mesin Fotokopi Dan Penannggulangannya (Study Kasus Di Q-El Copier Service
Center and Distributor)," JURTEKSI (Jurnal Teknol. dan Sist. Informasi), vol. 6, no. 2, pp. 163-172, 2020, doi: 10.33330/jurteksi.v6i2.548.

[7] Y. M. Paung, R. Titi, and Heryanto, "EFEKTIVITAS PENGENDALIAN INTERNAL PENJUALAN KREDIT RUMAH PADA PERUM PERUMNAS CABANG KALIMANTAN TIMUR," 2014.

[8] B. Cahyono, "ANALISIS SISTEM DAN PROSEDUR PEMBIAYAAN KREDIT PEMILIKAN RUMAH SYARIAH (KPRS) MURABAHAH UNTUK MENDUKUNG

PENGENDALIAN INTERN (Studi pada PT. BTN Syariah Cabang Jombang)," J. Adm. Bisnis S1 Univ. Brawijaya, vol. 25, no. 1, p. 86135, 2015.

[9] H. D. P. Hilda Savitri, "Klasifikasi Data Debitur Untuk Menentukan Kelayakan Kredit Dengan Menggunakan Metode Naive Bayes," no. November, pp. 1-8, 2018.

[10] N. V. Budiman, H. Karamoy, and V. Z. Tirayoh, "Analisis Sistem Pengendalian Internal Atas Penjualan Kredit Pada Pt. Rajawali Nusindo Cabang Manado," Going Concern J. Ris. Akunt., vol. 15, no. 3, p. 366, 2020 , doi: 10.32400/gc. 15.3.29674.2020. 